\title{
REVISED Cerebrospinal Fluid Biomarkers of Japanese
}

\section{Encephalitis [version 2; peer review: 3 approved]}

\author{
Nabonita Sengupta1, Sriparna Mukherjee1, Piyush Tripathi2, Rashmi Kumar (D)2, \\ Amol Ratnakar Suryawanshi ${ }^{3}$ Anirban Basu (iD)1
}

${ }^{1}$ National Brain Research Centre, Manesar, Haryana, 122051, India

2Department of Pediatrics, King George's Medical University, Lucknow, UP, 226003, India

${ }^{3}$ Clinical Proteomics Facility, Institute of Life Sciences, Bhubaneswar, Odisha, 751023, India

\author{
V2 First published: 23 Jul 2015, 4:334 \\ https://doi.org/10.12688/f1000research.6801.1 \\ Latest published: 03 Sep 2015, 4:334 \\ https://doi.org/10.12688/f1000research.6801.2
}

\section{Abstract}

Japanese encephalitis (JE) is the leading cause of viral encephalitis in Asia. Acute encephalitis syndrome (AES) is a group of central nervous system (CNS) disorders caused by a wide range of viruses, bacteria, fungi, chemicals and toxins. It is important to distinguish between various forms of infectious encephalitis with similar clinical manifestations in order to ensure specific and accurate diagnosis and development of subsequent therapeutic strategies. Cerebrospinal fluid (CSF) is in direct contact with the CNS and hence it is considered to be an excellent source for identifying biomarkers for various neurological disorders. With the recent advancement in proteomic methodologies, the field of biomarker research has received a remarkable boost. The present study identifies potential biomarkers for JE using a proteomics based approach. The CSF proteomes from ten patients each with JE and Non-JE acute encephalitis were analyzed by 2D gel electrophoresis followed by mass spectrometry. Vitamin Dbinding protein (DBP), fibrinogen gamma chain, fibrinogen beta chain, complement C4-B, complement C3 and cytoplasmic actin were found to be significantly elevated in case of JE indicating severe disruption of the blood brain barrier and DBP can be suggested to be an important diagnostic marker.

\section{Keywords}

Biomarkers , Japanese Encephalitis, Cerebrospinal fluid

\section{Open Peer Review}

Approval Status

1

2 3

version 2

(revision)

03 Sep 2015

version 1

23 Jul 2015

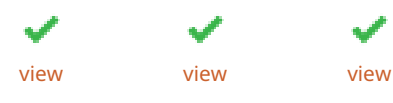

1. Akhil C. Banerjea, National Institute of Immunology, New Delhi, India

2. Anil Kumar, University of Missouri-Kansas City, Kansas City, USA

3. Daniel Růžek, Biology Centre of the Czech Academy of Sciences, České Budějovice, Czech Republic

Any reports and responses or comments on the article can be found at the end of the article. 
Corresponding author: Anirban Basu (anirban@nbrc.ac.in)

Competing interests: The authors declare no competing interests.

Grant information: AB is awarded the Tata Innovation Fellowship (ABS/DBT/0515/062) from the Department of Biotechnology. The project is also funded by National Brain Research Centre core funding. RK is funded by a grant from NBRC.

The funders had no role in study design, data collection and analysis, decision to publish, or preparation of the manuscript.

Copyright: @ 2015 Sengupta $\mathrm{N}$ et al. This is an open access article distributed under the terms of the Creative Commons Attribution License, which permits unrestricted use, distribution, and reproduction in any medium, provided the original work is properly cited. Data associated with the article are available under the terms of the Creative Commons Zero "No rights reserved" data waiver (CC0 1.0 Public domain dedication).

How to cite this article: Sengupta N, Mukherjee S, Tripathi P et al. Cerebrospinal Fluid Biomarkers of Japanese Encephalitis [version 2; peer review: 3 approved] F1000Research 2015, 4:334 https://doi.org/10.12688/f1000research.6801.2

First published: 23 Jul 2015, 4:334 https://doi.org/10.12688/f1000research.6801.1 


\section{REVISED Amendments from Version 1}

This version was published to update the name of one of the authors to: Amol Ratnakar Suryawanshi

See referee reports

\section{Introduction}

Non-infectious central nervous system (CNS) diseases can also have clinical presentations similar to those of infectious causes of encephalitis and should also be considered in the differential diagnosis ${ }^{1}$. Out of the viral forms of encephalitis, Japanese encephalitis (JE), is one of the most prevalent forms throughout the world, affecting mostly children and causes 15,000 deaths annually. Due to lack of suitable diagnostic strategies for Japanese encephalitis virus (JEV) and hence delayed treatment, the mortality rate of this disease is very high. Till date, JE can be diagnosed only with clinical symptoms, and serological examination of JE patients. Therefore, there is an urgent need for the development of effective treatment strategies which may be effective before the viral invasion in the brain and spinal cord. For this, an earlier diagnosis based on reliable biomarkers is essential to identify the status and intensity of JE infection. The extracellular fluid of the brain and spinal cord constitutes around 30 to $40 \%$ of the cerebrospinal fluid (CSF). Cerebrospinal fluid thus provides an accessible insight into the brain and hence is an ideal body fluid to examine for signature protein profiles for diagnosis or etiology of CNS-related disorders ${ }^{2}$.

\section{Methods}

Ethics statement

The study samples were obtained from the pediatric and adult medicine wards of King George's Medical University (KGMU) in Lucknow, Uttar Pradesh. KGMU Hospital is a teaching hospital which caters mostly to the poor and severely ill from the city and surrounding districts extending upto Nepal. Ethical approval was obtained from the Institutional Ethics Committee of King George's Medical University (KGMU), Lucknow. Written consent for CSF collection was obtained from the patient's guardian. The experiments were carried out in accordance with the institutional approved guidelines.

\section{CSF samples}

A total of 20 CSF samples were obtained from King George's Medical University, Lucknow for this study, These included 10 subjects each with JE and other forms of acute encephalitis respectively (Table 1). The lumbar puncture was done within 3 hours of

Table 1. Details of the cerebrospinal fluid samples from AES and JE patients.

\begin{tabular}{|l|l|l|}
\hline Sample Details & AE $(\mathbf{n}=\mathbf{1 0})$ & JE $(\mathbf{n}=\mathbf{1 0})$ \\
\hline Patient's Age & $4.5-50$ years & $4-45$ years \\
\hline Gender (male: female) & $7: 3$ & $8: 2$ \\
\hline Presence of IgM & JE IgM negative & JE IgM positive \\
\hline
\end{tabular}

admission of the patients and the CSF volume collected was 2-3 ml from each individual. Inclusion criteria for CSF collection in both $\mathrm{AE}$ and JE patients were: i) age $>3$ years but excluding pregnant women, ii) presence of fever with altered sensorium of 7 days or less. Exclusion criteria were: i) a firm alternative etiological diagnosis, ii) some contraindication to drug administration.

Enzyme linked immunosorbent assay (ELISA) tests

JE was confirmed by the presence of JE IgM in CSF using IgM Capture ELISA (MAC ELISA) kit developed by the National Institute of Virology (Pune) as per the manufacturer's instructions.

\section{Protein enrichment}

Due to the limited volume of the CSF samples, CSF samples from each experimental group were pooled by mixing equal volumes of each sample. The protein concentration of the samples was then determined by Bradford's method (Bradford Protein Assay Kit, Bio-Rad) according to the manufacturer's instructions. The respective CSF samples were then supplemented with $0.1 \%$ Triton X100 and protease inhibitors (Sigma Aldrich) and then filtered using a $0.45 \mu \mathrm{m}$ syringe filter to remove particulate matter, concentrated until the desired volume for protein enrichment was reached using a Freeze dryer (Martin Christ, Germany) and subjected to protein enrichment using Bio-Rad ProteoMiner ${ }^{\mathrm{TM}}$ Protein Enrichment Kit following the manufacturer's instructions to normalize the levels of high abundance proteins in the CSF.

\section{Sample preparation and proteomic analysis}

The enriched samples were then cleaned using 2D-clean up kit (Bio-Rad Laboratories, CA, US) following the manufacturer's instruction to remove impurities such as nucleic acids, lipids, and salts. 2-DE was performed as described earlier ${ }^{3}$. Briefly, the cleaned up protein pellet was resuspended in sample rehydration buffer and for the first dimension, isoelectric focusing was performed using immobilized $\mathrm{pH}$ gradient (IPG) strips (Bio-Rad, USA) of $7 \mathrm{~cm}$ size with a $\mathrm{pH}$ range from $3.0-10.0$ on a Protean i12TM IEF Cell (Bio-Rad, USA). For the second dimension, the proteins were separated by Tris glycine SDS-PAGE on $12 \%$ poly acrylamide gel by the method of Blackshear ${ }^{4}$. The protein spots were visualized by overnight staining with Brilliant Blue R-250, destained with $\mathrm{H}_{2} \mathrm{O}$, methanol, and acetic acid in a ratio of 50/40/10 (v/v/v) and scanned using Licor Odyssey Infra-red Imaging System. The protein spots visualized exclusively in the JE CSF proteome were excised and stored at $-80^{\circ} \mathrm{C}$ and processed later for in gel trypsin digestion as previously described ${ }^{5}$. The peptides extracted were analyzed by Matrix-assisted laser desorption/ionization-time of flight (MALDITOF/TOF) mass spectrometry using AB SCIEX TOF/TOFTM 5800 System. Acquired combined MS and MS/MS spectra were analyzed with ProteinPilot 4.0 Software using MASCOT v 2.3.02 search engine from matrix sciences against the taxonomy Homo sapiens. The peak list was searched against the taxonomy Homo sapiens at protein sequence Database: UniProtKB-SwissProt sprot_2014-04-16 (544996 sequences; 193815432 residues) Search parameters were as follows: Digestion: trypsin with one missed cleavage; Fixed modification: carbamidomethyl (c); variable modification: oxidation $(\mathrm{m})$; peptide mass tolerance: 100ppm for precursor ion and $0.8 \mathrm{Da}$ for fragment ion with +1 charge state; instrument: MALDI-TOF-TOF. 
CSF cytokine analysis

IL-8, IL-1 $\beta$, IL-6, IL-10, TNF $\alpha$, and IL-12 concentrations were measured by flow cytometry using a Human Inflammatory Cytokine CBA Kit, BD Cytometric Bead Array (a kind gift from Dr. Pankaj Seth, NBRC) (BD Biosciences, San Diego, CA, USA) as per the manufacturer's instructions ( $\mathrm{n}=3$ for each experimental group).

\section{Protein Interaction Analysis}

The associations of Vitamin D binding protein were explored using the STRING v10 clustering tool (http://string-db.org/). The confidence score was set at the highest level (0.900) and additional 20 nodes which were indirectly interacting with DBP were asked to show by the software.

\section{Results}

Dataset 1. Raw data of Cytokine Bead Analysis (CBA) of AE and JE infected CSF sample

http://dx.doi.org/10.5256/f1000research.6801.d89533

The datasheet contains the cytokine profile of three patients of $\mathrm{AE}$ and JE CSF samples.
Dataset 2. PDF version of the MALDI-TOF raw Data of the collected spots of JE CSF

http://dx.doi.org/10.5256/f1000research.6801.d89605

Each folder consists of two PDF files, one file contains the Mascot Search Result and the other file explains the identification of the protein.

Identification of potential biomarkers for JE in the CSF The specific JE associated proteins were identified by proteomic comparison of CSF from JEV-infected patients and patients with other forms of encephalitis. Around 16 proteins were found to be exclusively present in the JEV CSF proteome out of which 10 spots could be successfully identified (Figure 1). The observed MW and pI values of the protein spots on the 2- DE gels were compared with the theoretical MW and $\mathrm{pI}$ values of corresponding proteins (Table 2). The proteins identified were predominantly DBP, fibrinogen gamma chain, fibrinogen beta chain, complement C4-B, complement C3 and cytoplasmic actin. Most of the identified proteins were found to be members of the albumin multigene family.

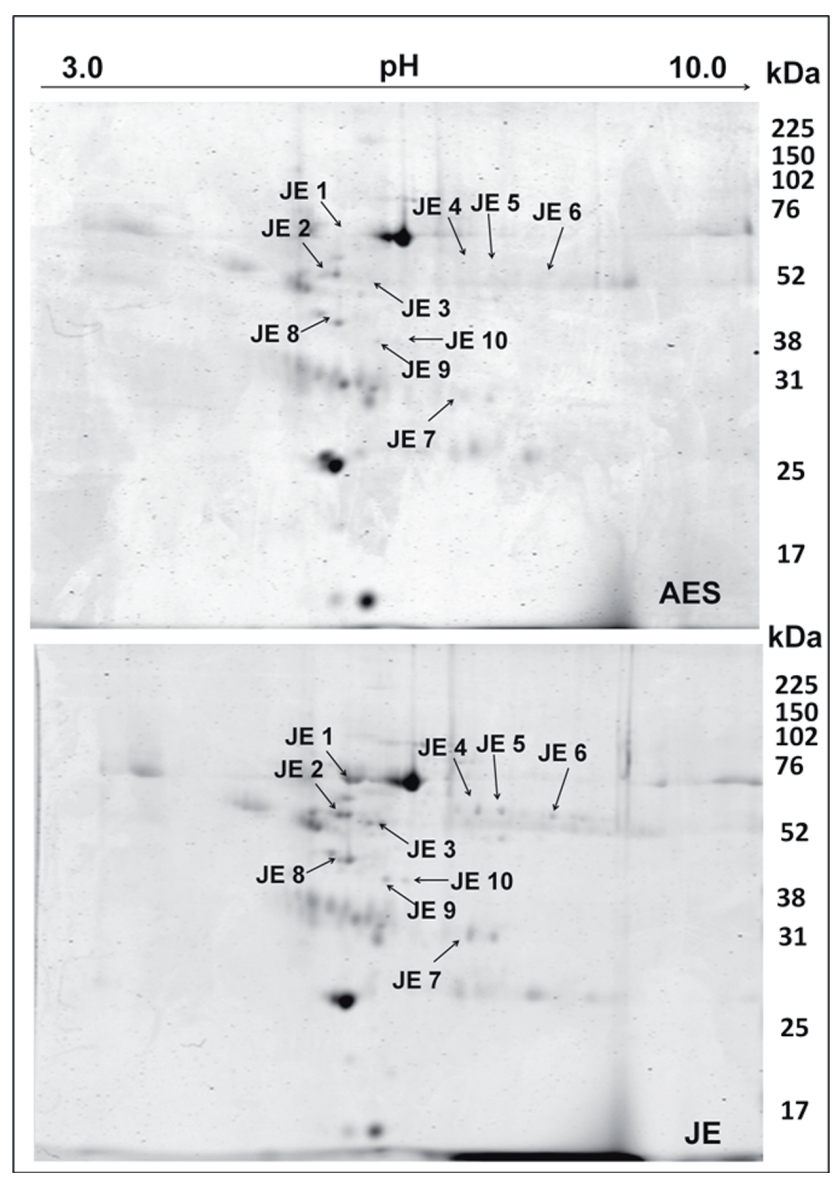

Figure 1. Comparative proteomic analysis of cerebrospinal fluid from AES and JEV patients. Cerebrospinal fluid samples were pooled and proteins were extracted and separated on immobilized linear pH gradient IPG strips (pH 3.0-10.0) and then in the second dimension on $12 \%$ SDS-PAGE. Spots exclusively visualized in the JE- CSF were marked and excised, and identified by MALDITOF/MS and database searches. The spots are labeled on the gel according to the numbers presented in Table 2. Images are representative of 4 replicate experiments. 
Table 2. Proteins exclusively visualized in the CSF of JEV infected patients, identified by MS/MS analysis of excised spots.

\begin{tabular}{|c|c|c|c|c|c|c|c|c|}
\hline $\begin{array}{l}\text { Sr. } \\
\text { No }\end{array}$ & $\begin{array}{l}\text { Spot } \\
\text { No. }\end{array}$ & $\begin{array}{l}\text { Protein ID. } \\
\text { (Accession) }^{\text {a }}\end{array}$ & Matched peptides & $\begin{array}{l}\text { lon } \\
\text { score }\end{array}$ & $\begin{array}{l}\% \\
\text { coverage }\end{array}$ & $\begin{array}{l}\text { Mowse } \\
\text { Score }\end{array}$ & $\begin{array}{l}\text { MW } \\
\text { (theorl } \\
\text { obs) }\end{array}$ & $\begin{array}{l}\text { pl } \\
\text { (theor/ } \\
\text { obs) }\end{array}$ \\
\hline 1. & $J E-1$ & $\begin{array}{l}\text { Serum albumin } \\
\text { (NP_000468) }\end{array}$ & $\begin{array}{l}\text { K.LVNEVTEFAK.T } \\
\text { K.SLHTLFGDKLCTVATLR.E } \\
\text { K.KYLYEIAR.R } \\
\text { K.YLYEIAR.R }\end{array}$ & $\begin{array}{l}30 \\
56 \\
56 \\
44\end{array}$ & 59 & 1480 & $71 / 70$ & $5.9 / 5.5$ \\
\hline 2. & JE-2 & $\begin{array}{l}\text { Vitamin D- } \\
\text { binding protein } \\
\text { (NP_000574) }\end{array}$ & $\begin{array}{l}\text { R.KFPSGTFEQVSQLVK.E } \\
\text { K.EVVSLTEACCAEGADPDCYDTR.T } \\
\text { K.SCESNSPFPVHPGTAECCTKEGLER.K } \\
\text { K.HQPQEFPTYVEPTNDEICEAFR.K } \\
\text { K.HLSLLTTLSNR.V }\end{array}$ & $\begin{array}{l}77 \\
89 \\
142 \\
74 \\
97\end{array}$ & 31 & 614 & $54 / 60$ & $5.4 / 5.4$ \\
\hline 3. & JE-3 & $\begin{array}{l}\text { Fibrinogen } \\
\text { gamma chain } \\
\text { (NP_000500) }\end{array}$ & $\begin{array}{l}\text { R.DNCCILDER.F } \\
\text { R.YLQEIYNSNNQK.I } \\
\text { K.QSGLYFIKPLK.A } \\
\text { K.IHLISTQSAIPYALR.V } \\
\text { K.IHLISTQSAIPYALR.V }\end{array}$ & $\begin{array}{l}34 \\
72 \\
50 \\
90 \\
36\end{array}$ & 24 & 595 & $52 / 54$ & $5.37 / 5.9$ \\
\hline 4. & JE-4 & $\begin{array}{l}\text { Fibrinogen beta } \\
\text { chain } \\
\text { (NP_005132) }\end{array}$ & $\begin{array}{l}\text { R.GHRPLDKK.R } \\
\text { K.HQLYIDETVNSNIPTNLR.V } \\
\text { R.SILENLR.S } \\
\text { R.TPCTVSCNIPVVSGKECEEIIR.K } \\
\text { R.QDGSVDFGR.K }\end{array}$ & $\begin{array}{l}22 \\
69 \\
21 \\
49 \\
40\end{array}$ & 35 & 286 & $56 / 60$ & $8.54 / 6.9$ \\
\hline 5. & JE-5 & $\begin{array}{l}\text { Fibrinogen beta } \\
\text { chain } \\
\text { (NP_005132) }\end{array}$ & $\begin{array}{l}\text { R.EEAPSLRPAPPPISGGGYR.A } \\
\text { K.HQLYIDETVNSNIPTNLR.V } \\
\text { R.SILENLR.S } \\
\text { R.QDGSVDFGR.K }\end{array}$ & $\begin{array}{l}19 \\
78 \\
26 \\
23\end{array}$ & 22 & 199 & $56 / 60$ & $8.54 / 7.2$ \\
\hline 6. & JE-6 & $\begin{array}{l}\text { Fibrinogen beta } \\
\text { chain } \\
\text { (NP_005132) }\end{array}$ & $\begin{array}{l}\text { R.GHRPLDK.K } \\
\text { R.EEAPSLRPAPPPISGGGYR.A } \\
\text { K.HQLYIDETVNSNIPTNLR.V } \\
\text { R.SILENLR.S } \\
\text { R.TPCTVSCNIPVVSGKECEEIIR.K }\end{array}$ & $\begin{array}{l}10 \\
19 \\
68 \\
26 \\
42\end{array}$ & 25 & 232 & $56 / 54$ & $8.54 / 7.7$ \\
\hline 7. & JE-7 & $\begin{array}{l}\text { Complement C4b } \\
\text { (NP_001002029) }\end{array}$ & $\begin{array}{l}\text { R.EAPKVVEEQESR.V } \\
\text { R.VHYTVCIWR.N } \\
\text { R.YVSHFETEGPHVLLYFDSVPTSR.E } \\
\text { R.ECVGFEAVQEVPVGLVQPASATLYDYYNPERR.C } \\
\text { R.RCSVFYGAPSK.S }\end{array}$ & $\begin{array}{l}88 \\
61 \\
115 \\
55 \\
18\end{array}$ & 17 & 864 & $194 / 31$ & $6.8 / 6.8$ \\
\hline 8. & JE-8 & $\begin{array}{l}\text { Actin, } \\
\text { cytoplasmic-1 } \\
\text { (NP_001092) }\end{array}$ & $\begin{array}{l}\text { K.AGFAGDDAPR.A } \\
\text { R.AVFPSIVGRPR.H } \\
\text { K.DSYVGDEAQSKR.G } \\
\text { K.DSYVGDEAQSKR.G }\end{array}$ & $\begin{array}{l}33 \\
53 \\
52 \\
120\end{array}$ & 48 & 1070 & $42 / 50$ & $5.29 / 5.4$ \\
\hline 9. & JE-9 & $\begin{array}{l}\text { Complement C4b } \\
\text { (NP_001002029) }\end{array}$ & $\begin{array}{l}\text { R.EAPKVVEEQESR.V } \\
\text { R.VHYTVCIWR.N } \\
\text { R.CSVFYGAPSK.S } \\
\text { R.LLATLCSAEVCQCAEGKCPR.Q } \\
\text { R.GLQDEDGYR.M }\end{array}$ & $\begin{array}{l}88 \\
60 \\
54 \\
142 \\
41\end{array}$ & 12 & 634 & $194 / 45$ & $6.8 / 6.0$ \\
\hline 10. & JE-10 & $\begin{array}{l}\text { Complement C3 } \\
\text { (NP_000055) }\end{array}$ & $\begin{array}{l}\text { K.VYAYYNLEESCTR.F } \\
\text { K.ACEPGVDYVYKTR.L } \\
\text { K.SGSDEVQVGQQR.T } \\
\text { K.SDDKVTLEER.L }\end{array}$ & $\begin{array}{l}90 \\
54 \\
49 \\
34\end{array}$ & 11 & 334 & $188 / 45$ & $6.02 / 4.8$ \\
\hline
\end{tabular}

aNCBI accession number of identified proteins is mentioned.

${ }^{\mathrm{b}} \mathrm{MS} / \mathrm{MS}$ data of 3 peptides for each spot was searched against NCBI database in the taxonomy group of Homo sapiens using Mascot tool.

The levels of two pro-inflammatory cytokines IL-1 $\beta$ and TNF $\alpha$ were found to be significantly elevated in JE patients as compared to AES patients while there was no remarkable change in the rest (Figure 2). The data were analyzed by Student's t-test and a statistical $p$ value $<0.05$ were considered significant.
The STRING v10 clustering tool was used to explore currently known associations of DBP (GC in Figure 3) and out of all the predicted functional partners, low density lipoprotein related protein-2 (LRP2) which is also known as megalin was found to have the highest interaction score (Figure 3). 
A.

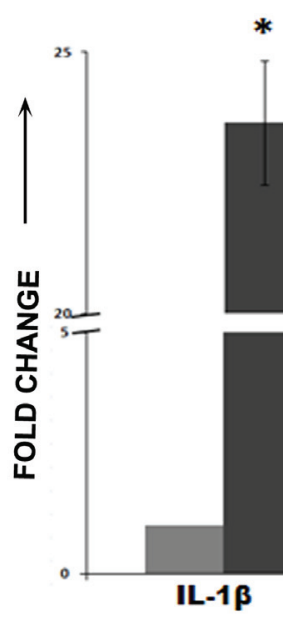

B.

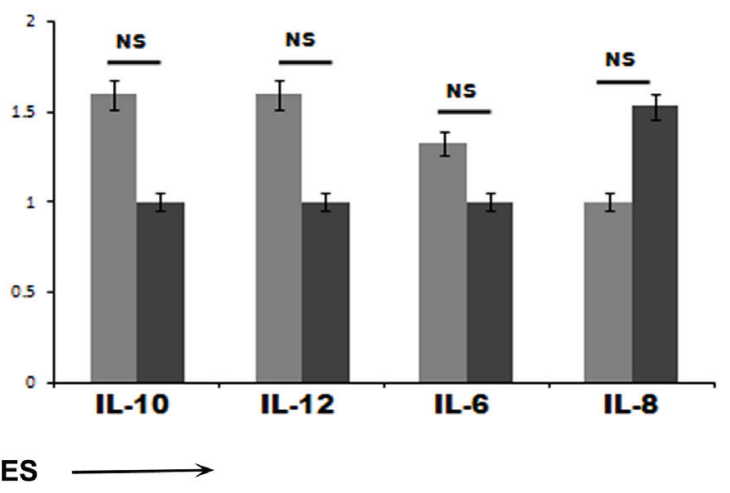

\section{AE JEV}

Figure 2. (A and B). Inflammatory cytokine profile of cerebrospinal fluid from AES and JEV patients. IL-8, IL-1 $\beta, I L-6, I L-10, T N F \alpha$, and IL-12 concentrations were measured by flow cytometry using Human Inflammatory Cytokine Kit (BD Biosciences, San Diego, CA, USA) as per manufacturer's instructions. Elevated levels of IL-1 $\beta$ and TNF $\alpha$ were observed in the JE samples (2A) whereas no significant changes were observed in the rest (2B). The image is a representative of 3 replicate experiments.

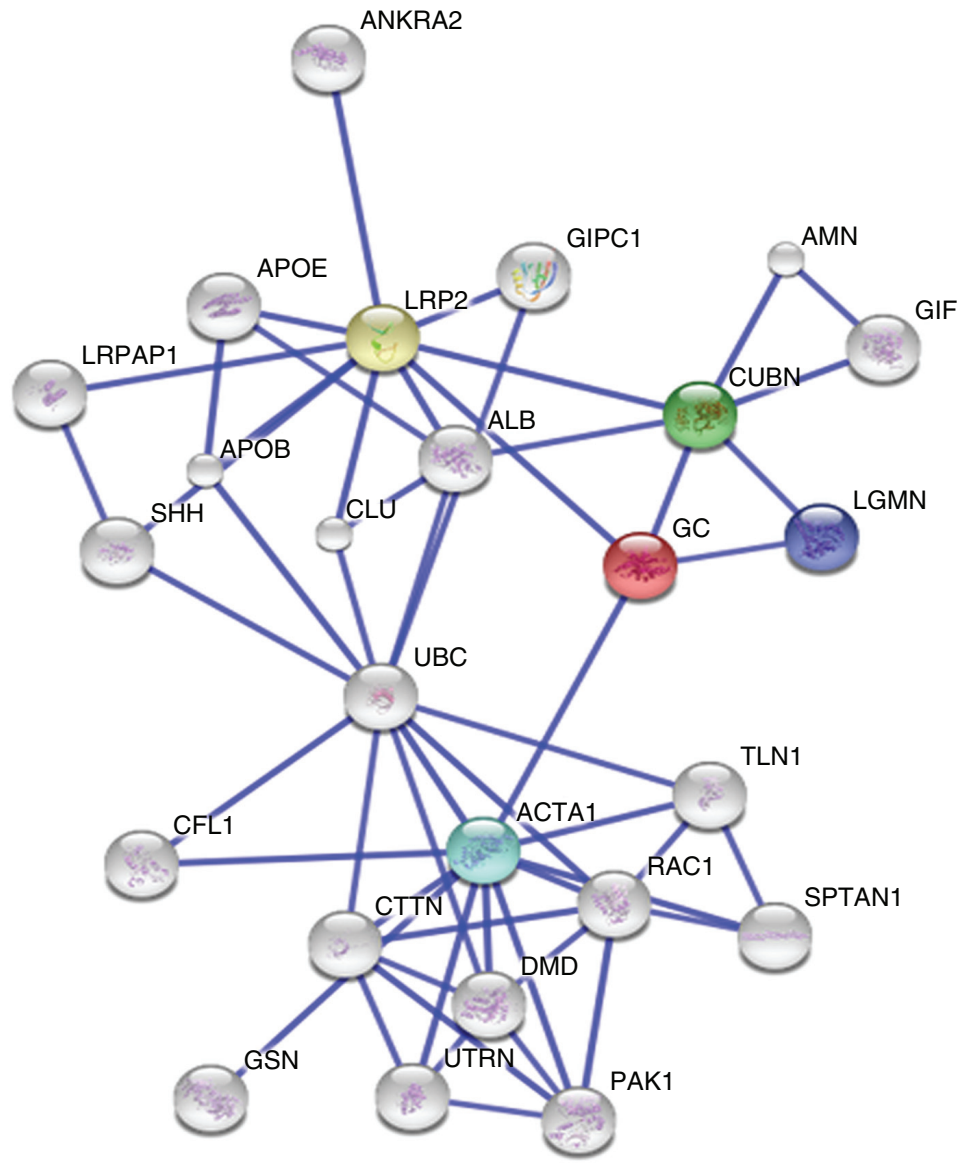

Figure 3. The associations of Vitamin D binding protein ('GC' in the figure) were explored using the STRING v10 clustering tool. The colored nodes signify a direct interaction with DBP whereas the white nodes denote a distant interaction. 4 proteins, LRP2 (yellow node), Cubilin (CUBN, green node), alpha 1 actin (ACTA1, blue node) and legumain (LGMN, violet node) are directly interacting with DBP and LRP2 is being shown the highest interacting score (0.983). 


\section{Discussion}

$\mathrm{JE}$ is one of the most dreaded forms of epidemic and sporadic encephalitis in the tropical regions of Asia with a very high mortality rate especially among children and young adults. The CSF proteome has been explored extensively for the identification of biomarkers for diseases like Alzheimer's disease, brain tumors, multiple sclerosis $^{6}$ but until now, few studies have investigated the association between imbalance of CSF elements and severity of JE infection. Recent advancements in proteomic approaches by mass spectrometry have aided the identification of useful predictive biomarkers. The present study provides the first insight into the potential CSF biomarkers associated with JEV neuroinvasion using proteomic methodologies. The CSF proteome from JEV infected individuals was compared to that of AES patients by 2DE-MS based approach. These experiments successfully identified a set of proteins with abnormal expression patterns in the CSF of JE patients which included 6 major proteins belonging to the albumin multigene family. One of the most interesting findings was the DBP which is an abundant multifunctional protein with roles in vitamin D metabolite transport, actin sequestration, and regulation of immune responses ${ }^{7}$. In a recent study, Yang et al. ${ }^{8}$ reported DBP to be a potential diagnostic biomarker for the progression of multiple sclerosis where this protein has been shown to interact with actin and play an important role in removal of excess actin. In addition elevated levels of DBP were also shown to be adverse to recovery. Interestingly, we have also observed an increase in the levels of cytoplasmic actin in the CSF of JE patients as opposed to that of patients with AES. Elevated levels of cytoplasmic actin in the CSF have been previously related to severe axonal degeneration associated with progressive multiple sclerosis ${ }^{9}$. Hence the abnormal levels of the aforementioned interacting proteins in case of JE may be attributed to the extensive neurodegeneration taking place in the CNS. Another important finding was the abnormal increase in the levels of complement proteins $\mathrm{C} 3$ and $\mathrm{C} 4 \mathrm{~b}$. It has been previously suggested that the activation of the complement system is involved in the pathogenesis of several neurodegenerative diseases like Alzheimer's disease, Parkinson's disease, and multiple sclerosis ${ }^{10}$. A recent study has also shown that complement $\mathrm{C} 3$ is causally involved in the inflammatory neurodegeneration ${ }^{11}$. Some studies have also shown that DBP can enhance complement component 5a-mediated macrophage chemotaxis via binding to $\mathrm{C}^{2} \mathrm{a}^{12}$. We also detected elevated levels of fibrinogen beta and gamma chains as well as serum albumin in the CSF of JE patients. Fibrinogen and serum albumin are normally excluded from the brain by the blood brain barrier (BBB) and their presence in the CSF is an obvious sign of the disruption of the BBB during JE infection. A recent study has shown that fibrinogen leakage upon $\mathrm{BBB}$ disruption triggers perivascular microglial clustering in turn causing neuroinflammation and subsequent axonal damage ${ }^{13}$. Hence the accumulation of fibrinogen in the cerebral parenchyma may play a critical role in neuroinflammation and JE pathogenesis.

In our study, DBP, complement proteins $\mathrm{C} 3$ and $\mathrm{C} 4 \mathrm{~b}$ and fibrinogen beta and gamma chain were found to be increased in expression in JE patients when compared to AES patients. Elevated levels of proinflammatory cytokines like IL-1 $\beta$ and TNF $\alpha$ were indicative of peripheral immune activation subsequently leading to an up-regulation of CNS cytokine production ${ }^{14}$. Since DBP has been an important finding of this study, an attempt was made to explore the interacting partners of this protein in order to decipher its possible role in JEV neuropathogenesis using STRINGv10 cluster analysis tool ${ }^{15}$. LRP-2 or megalin was found to have the highest interaction score. LRP-2 belongs to a group of surface endocytic receptors, which bind and internalize extracellular ligands which also include DBP and is known to play a key role in the clearance and entrance of many proteins from the brain or $\mathrm{CSF}^{16}$. These findings highlight a severe disruption of the BBB during JE infection ultimately leading to subsequent pathogenesis and neurodegeneration and DBP may have an important role as a potential JEV biomarker which can be established with further studies.

\section{Conclusion}

We can suggest that DBP may be an important marker for JE. Further studies need to be carried out to further validate this putative biomarker.

\section{Data availability}

F1000Research: Dataset 1. Raw data of Cytokine Bead Analysis (CBA) of AE and JE infected CSF samples. The datasheet contains the cytokine profile of three patients of AE and JE CSF samples. 10.5256/f1000research.6801.d89533 ${ }^{17}$

F1000Research: Dataset 2. PDF version of the MALDI-TOF raw Data of the collected spots of JE CSF.

Each folder consists of two PDF files, one file contains the Mascot Search Result and the other file explains the identification of the protein. 10.5256/f1000research.6801.d89605 ${ }^{18}$

\section{Author contributions}

$\mathrm{AB}, \mathrm{NS}$ and SM designed the experiments. NS and SM performed the experiments. $\mathrm{AB}$ and NS wrote the main manuscript and prepared the figures. RK and PT collected the samples. Mass Spectrometry was performed by AS. All authors reviewed the manuscript.

\section{Competing interests}

The authors declare no competing interests.

\section{Grant information}

AB is awarded the Tata Innovation Fellowship (ABS/DBT/0515/062) from the Department of Biotechnology. The project is also funded by National Brain Research Centre core funding. RK is funded by a grant from NBRC.

I confirm that the funders had no role in study design, data collection and analysis, decision to publish, or preparation of the manuscript.

\section{Acknowledgements}

The authors would like to acknowledge the kind help provided by R. Rajendra Kumar Reddy, Central Proteomics Facility at Institute of Life Sciences, Bhubaneswar, India. 
1. Tunkel AR, Glaser CA, Bloch KC, et al:: The management of encephalitis: clinical practice guidelines by the Infectious Diseases Society of America. Clin Infect Dis. 2008; 47(3): 303-327.

PubMed Abstract | Publisher Full Text

2. Ransohoff RM: Immunology: Barrier to electrical storms. Nature. 2009; 457(7226): 155-156.

PubMed Abstract | Publisher Full Text

3. Sengupta N, Ghosh S, Vasaikar SV, et al: Modulation of neuronal proteome profile in response to Japanese encephalitis virus infection. PLOS One. 2014; 9(3): e90211.

PubMed Abstract | Publisher Full Text | Free Full Text

4. Blackshear PJ: Systems for polyacrylamide gel electrophoresis. Methods Enzymol. 1984; 104: 237-255.

PubMed Abstract | Publisher Full Text

5. Khan SA, Suryawanshi AR, Ranpura SA, et al:: Identification of novel immunodominant epididymal sperm proteins using combinatorial approach. Reproduction. 2009; 138(1): 81-93. Reproduction. 2009; 138(1): 81-93.
PubMed Abstract | Publisher Full Text

6. Blennow K, Zetterberg H: Cerebrospinal fluid biomarkers for Alzheimer's disease. J Alzheimers Dis. 2009; 18(2): 413-417.

PubMed Abstract | Publisher Full Text

7. Gomme PT, Bertolini J: Therapeutic potential of vitamin D-binding protein. Trends Biotechnol. 2004; 22(7): 340-345. PubMed Abstract | Publisher Full Text

8. Yang M, Qin Z, Zhu Y, et al:: Vitamin D-binding protein in cerebrospinal fluid is associated with multiple sclerosis progression. Mol Neurobiol. 2013; 47(3): 946-956.

PubMed Abstract | Publisher Full Text

9. Teunissen CE, Dijkstra C, Polman C: Biological markers in CSF and blood for axonal degeneration in multiple sclerosis. Lancet Neurol. 2005; 4(1): 32-41. PubMed Abstract | Publisher Full Text

10. Finehout EJ, Franck Z, Lee KH: Complement protein isoforms in CSF as possible biomarkers for neurodegenerative disease. Dis Markers. 2005; 21(2): 93-101. PubMed Abstract | Publisher Full Text | Free Full Text

11. Bodea LG, Wang Y, Linnartz-Gerlach B, et al:: Neurodegeneration by activation of the microglial complement-phagosome pathway. J Neurosci. 2014; 34(25) 8546-8556.

PubMed Abstract | Publisher Full Text

12. Kew RR, Webster RO: Gc-globulin (vitamin D-binding protein) enhances the neutrophil chemotactic activity of C5a and C5a des Arg. J Clin Invest. 1988; 82(1): 364-369.

PubMed Abstract | Publisher Full Text | Free Full Text

13. Davalos D, Ryu JK, Merlini M, et al:: Fibrinogen-induced perivascular microglial clustering is required for the development of axonal damage in neuroinflammation. Nat Commun. 2012; 3: 1227.

PubMed Abstract | Publisher Full Text | Free Full Text

14. Lampa J, Westman M, Kadetoff D, et al:: Peripheral inflammatory disease associated with centrally activated IL-1 system in humans and mice. Proc Natl Acad Sci U S A. 2012; 109(31): 12728-12733.

PubMed Abstract | Publisher Full Text | Free Full Text

15. Szklarczyk D, Franceschini A, Wyder S, et al.: STRING v10: protein-protein interaction networks, integrated over the tree of life. Nucleic Acids Res. 2015; 43(Database issue): D447-452.

PubMed Abstract | Publisher Full Text | Free Full Text

16. Spuch C, Ortolano S, Navarro C: LRP-1 and LRP-2 receptors function in the membrane neuron. Trafficking mechanisms and proteolytic processing in Alzheimer's disease. Front Physiol. 2012; 3: 269. PubMed Abstract | Publisher Full Text | Free Full Text

17. Sengupta N, Mukherjee S, Tripathi P, et al.: Dataset 1 in: Cerebrospinal Fluid Biomarkers of Japanese Encephalitis. F1000Research. 2015. Data Source

18. Sengupta N, Mukherjee S, Tripathi P, et al.: Dataset 2 in: Cerebrospinal Fluid Biomarkers of Japanese Encephalitis. F1000Research. 2015 Data Source 


\section{Open Peer Review}

\section{Current Peer Review Status:}

\section{Version 1}

Reviewer Report 31 July 2015

https://doi.org/10.5256/f1000research.7311.r9609

(C) 2015 Růžek D. This is an open access peer review report distributed under the terms of the Creative Commons Attribution License, which permits unrestricted use, distribution, and reproduction in any medium, provided the original work is properly cited.

\section{Daniel Růžek}

Institute of Parasitology, Biology Centre of the Czech Academy of Sciences, České Budějovice, Czech Republic

Sengupta et al. submitted a research article reporting novel CSF biomarkers of Japanese encephalitis (JE). JE is a leading cause of viral encephalitis in Asia. However, there are still many gaps in our understanding of the pathogenesis of JE in humans. Early diagnosis based on reliable biomarkers is essential to identify the status and intensity of JE infection. Here, the authors compared CSF proteomes from ten patients with JE and ten patients with another form of acute encephalitis by 2D gel electrophoresis followed by mass spectrometry. The analysis identified elevated levels of vitamin D-binding protein (DBP), fibrinogen gamma chain, fibrinogen beta chain, complement C4-B, complement C3 and cytoplasmic actin in CSF from JE patients. This indicates blood-brain barrier disruption, and the DBP also represents a novel and mechanistically important CSF biomarker of JE. The exact role of DBP in the development of JE will be investigated is further studies.

The manuscript is well written, easy to follow, and provides very important data to all interested in the mechanisms of pathogenesis of neurotropic flaviviral infections. I fully recommend accepting the manuscript for indexation.

Minor comments:

1. I would be interested to know more details on the other forms of the acute encephalitis involved in the study. In the next studies, it would be interesting to compare different forms of encephalitis more specifically, like JE vs. TBE, JE vs. herpetic encephalitis, etc.

2. In the next studies, it would be useful to investigate the biomarker levels in individual patients or to make more pools for each group. In case of one pool investigated, it is not fully clear if the levels of biomarkers are increased in all or most of the patients or if there is just only a strong production in one patient.

Competing Interests: No competing interests were disclosed. 


\title{
I confirm that I have read this submission and believe that I have an appropriate level of expertise to confirm that it is of an acceptable scientific standard.
}

Reviewer Report 30 July 2015

https://doi.org/10.5256/f1000research.7311.r9714

(C) 2015 Kumar A. This is an open access peer review report distributed under the terms of the Creative Commons Attribution License, which permits unrestricted use, distribution, and reproduction in any medium, provided the original work is properly cited.

\begin{abstract}
Anil Kumar
Division of Pharmacology and Toxicology, School of Pharmacy, University of Missouri-Kansas City, Kansas City, MO, USA

The manuscript entitled "Cerebrospinal Fluid Biomarkers of Japanese Encephalitis" by Sengupta and colleagues reports their novel findings unique biomarkers for an important disease wherein encephalitis caused by Japanese Encephalitis Virus causes almost 15,000 deaths every year. Currently the JEV infection can be diagnosed only by using serology and clinical symptoms. Therefore there is an urgent need to identify biomarker(s) for this disease. They used cerebrospinal fluid from $10 \mathrm{JE}$ and $10 \mathrm{AE}$ patients and performed 2D and mass spectrometry on these samples. They observed 6 different proteins that were significantly increased in JE patients. They also found that IL-1 $\beta$ and TNF- $\alpha$ were also significantly elevated in JE patients. Their further analysis indicated DBP as potential biomarker in JE patients.

Both the Tables and 3 figures are necessary and results in these items support the conclusions very well stated in the manuscript. This manuscript would be extremely useful to the people involved in the general area of JE research and particularly to those involved in diagnostics. The manuscript is well written and this study provides a very important and significant advancement in the field.

Competing Interests: No competing interests were disclosed.

I confirm that I have read this submission and believe that I have an appropriate level of expertise to confirm that it is of an acceptable scientific standard.
\end{abstract}

Reviewer Report 29 July 2015

https://doi.org/10.5256/f1000research.7311.r9697

(C) 2015 Banerjea A. This is an open access peer review report distributed under the terms of the Creative Commons Attribution License, which permits unrestricted use, distribution, and reproduction in any medium, provided the original work is properly cited.

\section{Akhil C. Banerjea}


Laboratory of Virology, National Institute of Immunology, New Delhi, Delhi, India

This paper is a significant addition to our knowledge in JE encephalitis and have identified markers using proteomic approach that would also suggest damage to the blood brain barrier. The experiments carried out support the conclusions. I recommend indexation. The DBP as marker will need more JE and non-JE cases to confirm - so they must indicate that possibility.

Competing Interests: No competing interests were disclosed.

I confirm that I have read this submission and believe that I have an appropriate level of expertise to confirm that it is of an acceptable scientific standard.

The benefits of publishing with F1000Research:

- Your article is published within days, with no editorial bias

- You can publish traditional articles, null/negative results, case reports, data notes and more

- The peer review process is transparent and collaborative

- Your article is indexed in PubMed after passing peer review

- Dedicated customer support at every stage

For pre-submission enquiries, contact research@f1000.com 